\title{
The use of ICT in the first grade of primary school for teaching circles, triangles, rectangles and squares
}

\author{
Nicholas Zaranis \\ Department of Preschool Education, \\ Faculty of Education, University of \\ Crete, Greece \\ nzaranis@edc.uoc.gr
}

\begin{abstract}
The purpose of this study is to investigate if information and communications technology (ICT) helps to improve first grade students' basic geometry achievement regarding circles, triangles, rectangles and squares. Our research compares the level of geometrical competence of the students taught using our ICT oriented learning method specifically targeting 'Realistic Mathematics Education' (RME) for geometry concepts, as opposed to traditional teaching methodology. The designed software consisted of a story and several activities with and without the use of computers for circles, triangles, rectangles and squares. It was designed following the background of RME theory for geometry concepts. The study dealt with first grade students in Crete and Athens, who were divided into two groups (experimental and control). The experimental group consisted of 113 students who were taught about circles, triangles, rectangles and squares.with the support of computers. There were 121 students in the control group which were not exposed to the computer oriented curriculum. Students in both groups were pretested and post-tested for their geometry performance. The results of the study indicated that teaching and learning through ICT is an interactive process for students at the first grade level and has a positive effect for the learning of circles, triangles, rectangles and squares.using the background of RME theory. Also, the most important outcome of this study was that this teaching intervention seemed to be more effective for triangles and rectangles than for circles and squares.
\end{abstract}

\section{Keywords}

ICT, Realistic Mathematics, geometry, circles, triangles, rectangles, squares, primary education.

\section{INTRODUCTION}

Nowadays, it is widely accepted that information and communication technologies are used in every steps of education [1], [2], [3]. Technology acts as a catalyst in children, provides social interaction and moreover provides additional opportunities for a rich learning environment that is consistent with modern times [4]. Although concerns about developmental convenience of technology have been announced, many studies have determined that technology has had positive influences on children cognitive and sensual developments [5], [6].

A growing body of literature provides increasing evidence of the effectiveness of using computer technologies to facilitate instruction and learning across a variety of school subjects [7], [8], [9], [10]. Particularly, studies have demonstrated that computers have supported the development of the abilities in children's memory, problem-solving, literacy and math [11], [12], [13], [14], [15], [16]. Indeed, ICT can play an essential role in achieving the objectives of the kindergarten curriculum if supported by appropriate software applications embedded in appropriate educational scenarios [17], [18], [19].

\section{ICT AND MATHEMATICS}

In the most ideal setting, information communication technologies are treated as a tool for teaching and learning [20], [21], [22]. They are used as a tool for the students to become more familiar with new technology and to integrate investigation, communication and understanding across the full range of the curriculum. Particularly, in the cognitive field of mathematics an evaluation of learning outcomes regarding computer based mathematical teaching in students showed that computer-assisted learning can significantly help in developing proper mathematical skills and the cultivation of deeper conceptual thinking in comparison to the traditional mathematical teaching method [23], [24], [25].

Researchers suggest that the mathematical difficulties students encounter later are correlated with insufficient development of mathematical thinking in their early years [26], [27]. Various researches' results relate the appropriate use of computers with the ability of students to more efficiently understand the different mathematical notions [28], [29]. Thus, it becomes obvious that in the primary school level a very attractive environment of investigating the computer use in mathematics education emerges. Indeed, a vast number of studies show a positive interrelation between the use of computers and the development of mathematical thinking in school [8], [30]. Nonetheless, computer based activities should reflect the theoretical ideas behind them [31], [32].

Following this principle, the software designed and the students' activities developed and examined for the purposes of the current study were inspired by the framework of Realistic Mathematics Education (RME). RME was based and developed principally upon Freudenthal's [33] view of mathematics as a "human activity." According to his perspective, in order for mathematics to be of human value, it has to be taught so as to be useful, it has to be closely related to reality, close to children and relevant to the society [33], [34]. RME is an active and constantly evolving theory of teaching and learning mathematics [35]. Indicative of this, the learning and teaching trajectories with intermediate attainment targets were first conducted for the subject of mathematical calculation at the primary school level and extended to the subject of geometry [36].

In the whole trajectory of the RME teaching theory, five main characteristics of understanding geometry concepts are involved: (a) introducing a problem using a realistic context; (b) identifying the main objects of the problem; (c) using appropriate social interaction and teacher intervention to refine the models of the problem; (d) encouraging the process of reinvention with the 
development of the problem; and (e) focusing on the connections and aspects of mathematics in general [35]. These should be the main focuses of the learning and teaching procedure concerning geometry in primary school.

Following the theoretical framework that blends together Realistic Mathematics Education (RME) and the use of ICT in primary school, we designed a new model referred to as the First Class Primary Shape Model (FCPSM) which consisted of five levels.

The majority of previous studies aggregately examined the effects of various teaching on the geometric shapes. However, a small number of studies have found that in the first levels of primary school, various shapes are understood differently by students [16], [37]. These studies examined the impact of various teaching interventions on each shape distinctively. Specifically, in the case of circles and squares, only the thickness and size may be varied. Rectangles and triangles may also share differences in characteristics of thickness and size with the addition of other variable characteristics such as length of sides and orientation. Moreover, triangles may vary in the degree of their angles, resulting in a greater variety of shapes. Thus, from the perspective of characteristic features, circles and squares are the simplest. On the contrary, triangles are the most complex, and rectangles are of intermediate difficulty [38], [39].

Our study was based on the above mentioned international literature; we set out to investigate the following research question: Is the concept of triangles more difficult to understand than circles for the first grade students?

In addition, based on the previous studies, we set out to investigate the following hypotheses:

1. The students who will be taught circles with educational intervention based on FCPSM will have a significant improvement in comparison to those taught using the traditional teaching method according to the first grade curriculum.

2. The students who will be taught triangles with educational intervention based on FCPSM will have a significant improvement in comparison to those taught using the traditional teaching method according to the first grade curriculum.

3. The students who will be taught rectangles with educational intervention based on FCPSM will have a significant improvement in comparison to those taught using the traditional teaching method according to the first grade curriculum.

4. The students who will be taught squares with educational intervention based on FCPSM will have a significant improvement in comparison to those taught using the traditional teaching method according to the first grade curriculum.

The present study makes an important contribution to the literature; we examined and compared the effects of a new model which combines computer and non-computer activities for teaching circles, triangles, rectangles and squares separately.

\section{METHODOLOGY}

The present research was conducted in three phases. In the first and third phases, the pre-test and post-test were given to the classes respectively. In the second phase, the teaching intervention was performed.

\subsection{Subjects}

The study was carried out during the 2011-12 school year in ten public primary schools located in the cities of Rethymno in Crete (two classes) and Athens (eight classes). It was an experimental research which compared the FCPSM teaching process to traditional teaching based on first grade curriculum. The sample included 234 first graders consisting of 123 girls and 111 boys age six to seven years old. There were two groups in the study, one control $(n=121)$ and one experimental $(n=113)$. In the control group there was not a computer available for the students' use. The classes in the experimental group, in order to participate, were required to have a laptop computer and a video projector available for use by children as part of the teaching procedure. For the uniformity of the survey, instructions were given to the teachers who taught in the experimental or control groups. Teachers who participated in the study had university degrees in education. The teachers in the experimental group ranged from 40 to 50 years old with in-service teaching experience ranging from 18 to 28 years. The teachers in the control group were of ages 38 to 48 years old with in-service teaching experience ranging from 15 to 25 years.

\subsection{Instructional Intervention}

In the second phase the control group taught with traditional teaching according to first grade curriculum. Group and individual activities were given to children every day. The experimental group covered the same material at roughly the same time according to the FCPSM teaching. The content of the four week syllabus of the FCPSM divided in five levels. It comprised of shapes including a variety of topics concerning fundamental geometry as circles, triangles, rectangles and squares.

The first level of the teaching intervention was according to the first characteristic of the teaching theory of RME which introduces a problem using a realistic context. In this level a story called 'The Family of Shapes' was presented to the students. Various geometrical shapes including circles, triangles, rectangles and squares are presented in this story in a fictional family setting where each member of the family represents a particular shape. This story was designed using Flash CS3 Professional Edition and presented with the video projector in the classroom. In this story Mrs. Square and Mr. Triangle had a daughter Miss Circle. Later in the story, Miss Circle met Mr. Rectangle, they got married (see Figure 1) and had many children that looked like their parents and grandparents.

The second level started with an activity which identifies the main objects of the problem as underlined by the RME theory. According to the second characteristics of the RME theory, the students (a) identified various geometrical shapes by examining objects in their classrooms, (b) drew certain geometrical shapes (see Figure 2) and (c) named the shape of a set of various objects presented to them by the teacher.

The third level of the teaching procedure included activities using appropriate social interaction to refine the models of the problem. Firstly, a child had to draw a shape from a bag and to find out the name of the shape without seeing it. Then, the students split into groups and each group had to construct a dog or a man using a set of shapes. The final part of this level involved a computer-based group activity in which the student had to recognize and choose the correct shape among other shapes (see Figure 3).

In the fourth level of the teaching procedure, according to the RME theory, we implemented a process of reinvention with the development of the shapes in a higher cognitive level where the properties of an object were presented in a software activity. Next, the children were separated into groups and cooperated with one another to make a shape with their bodies on the floor. Then, they 
divided into groups and each group was assigned a specific shape. Each of these groups was instructed to make fake cookies from plasticine in the form of the groups' assigned shape (see Figure 4). At the end of this activity, the students in each group shared their cookies with the other groups.

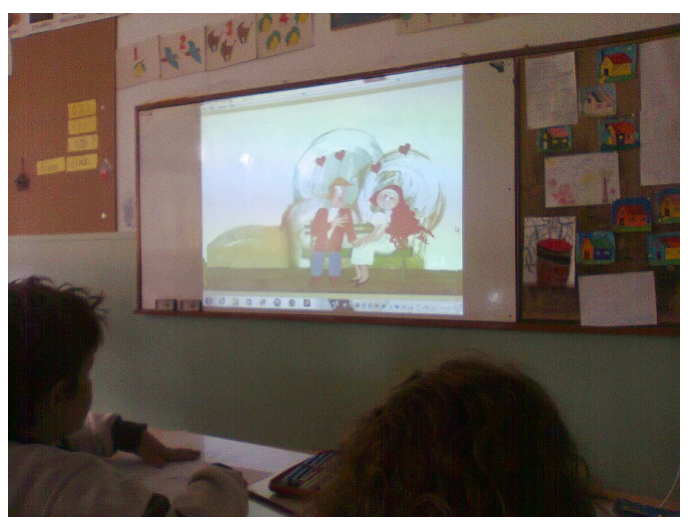

Figure 1. Students watched the story 'The Family of Shapes' (first level).

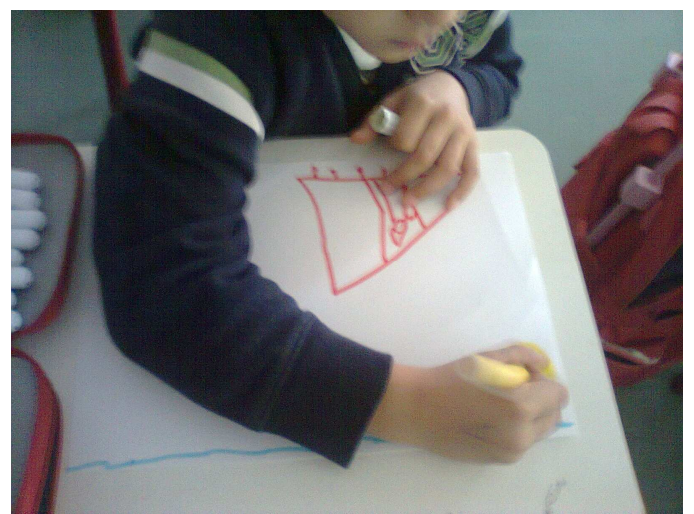

Figure 2. The student did a drawing activity (second level).

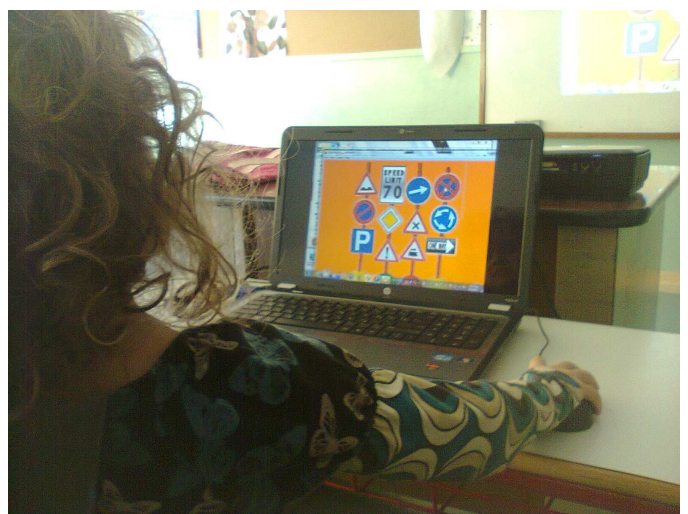

Figure 3. The student had to recognize shapes (third level).

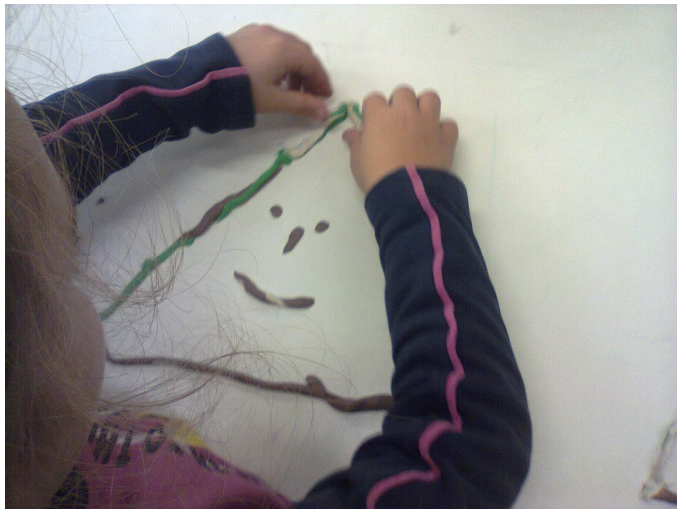

Figure 4. Each student was instructed to make fake cookies from plasticine (fourth level).

In the last level of the teaching process, the students played card games with the properties of shapes. The goal of this card game is to focus on the connections and aspects of the properties of circles and triangles as implied by the fifth characteristic of the RME theory. There were two kinds of card games: the white cards with shapes and their properties of sides and the yellow cards with shapes and their properties of angles. The students are separated into groups and each student in a group starts with a number of cards in their hand. Each student takes his/her turn throwing a card on the table. The purpose of the game is to match cards with identical properties and to collect those cards. At the end of the game the child who had the majority of cards was the winner. Afterwards, there were computer activities where the children had to recognize the shapes from using only the properties of the shapes. The computer presents a picture as a puzzle. The students then must drag and drop the corresponding shape, based the geometrical property displayed on the screen, into the box (see Figure 5).

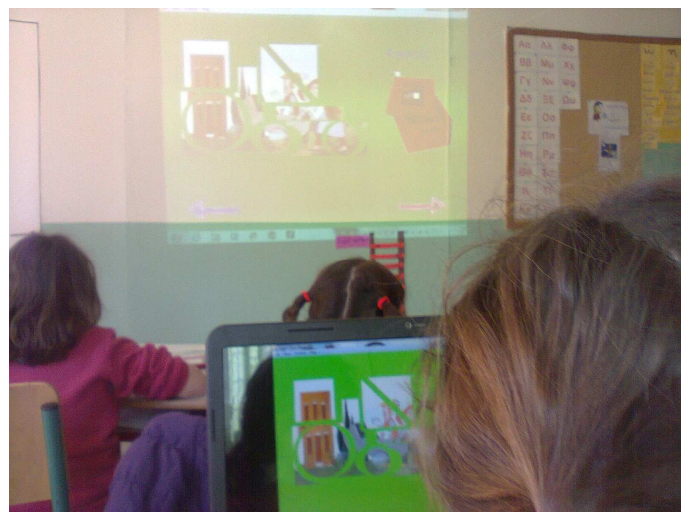

Figure 5. Students completed a software activity (fifth level).

In the software represented above, once an activity is selected, a problem is announced verbally and directions are given to the user through a recorded message. The feedback users get after following these directions is represented by two different screens, one positive and one negative. This feedback is accompanied with the corresponding audio messages. In the first case, the user receives a 'well-done' message (see Figure 6) and in the second case the user gets a 'try it again' message. In both cases, though, an effort was made to keep these messages to be as little emphatic 
as possible. This way, the children's' interest is focused more on the mathematical procedure of the application rather than their result or the competition.

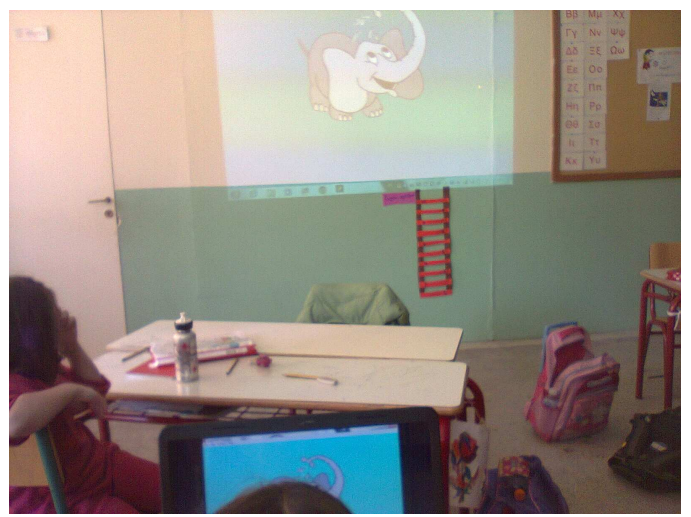

Figure 6. The user receives a 'well-done' message.

\subsection{Educational Measures}

In the first phase, the pre-test was given to the classes of the experimental and control groups during the beginning of December 2011 to isolate the effects of the treatment by looking for inherent inequities in the geometry achievement potential of the two groups. The pre-test was referred to as First Class Primary Shape Test (FCPST) and it contained thirty tasks in total. The first twenty tasks of the FCPST were based on the first level of the Van Hiele model and the last ten were from the test that was used in the research by Clements et al. [40] based on the second van Hiele level.

The theory of the van Hiele model deals specifically with geometric thought as it develops through several levels of sophistication under the influence of a school curriculum [41]. The van Hiele model uses five levels, however, for the first grade students only the first two levels were used. In the Visual Level, students were able to identify figures such as circles and triangles as visual gestalts. Conceptualization at this level includes being able to name, reproduce and group similar geometric objects by visual recognition. For instance, they might say that a figure is a rectangle because it looks like a door. In the Descriptive/Analytic Level, students were able to identify shapes from their properties. Conceptualization at this level includes identifying geometric objects according to their properties. For example, a student sees a rhombus as a figure with four equal sides [42].

Due to the young age of the students, the pre-tests were administrated in the class with explicit and detailed instructions of the teacher. These were pencil-and-paper tasks in which the children were asked to select shapes including rectangles, squares, triangles and circles on a page with various geometric figures (see Figure 7). Each task had a weighted grade that was computed from the student's answers. Particularly, for each correct answer the student was given one grade and lost one grade for each incorrect. Scores were computed for each of the individual geometrical tasks of the FCPST. Since the numbers of problems varied across tasks, a mean proportion of correct responses for each of the thirty tasks were produced by dividing the number of correct responses by the total number of problems on that task (possible range of standardized scores, 0-1.00). Moreover, for the purposes of the present study, we measured the score of circles and the score of the triangles separately. The scale used to measure the unstandardized scores for circles is based on a scale from 0 to 69 and for squares is from 0 to 67 . The scale used to measure the unstandardized scores for triangles is based on a scale from 0 to 40 and for rectangles is from 0 to 41 .

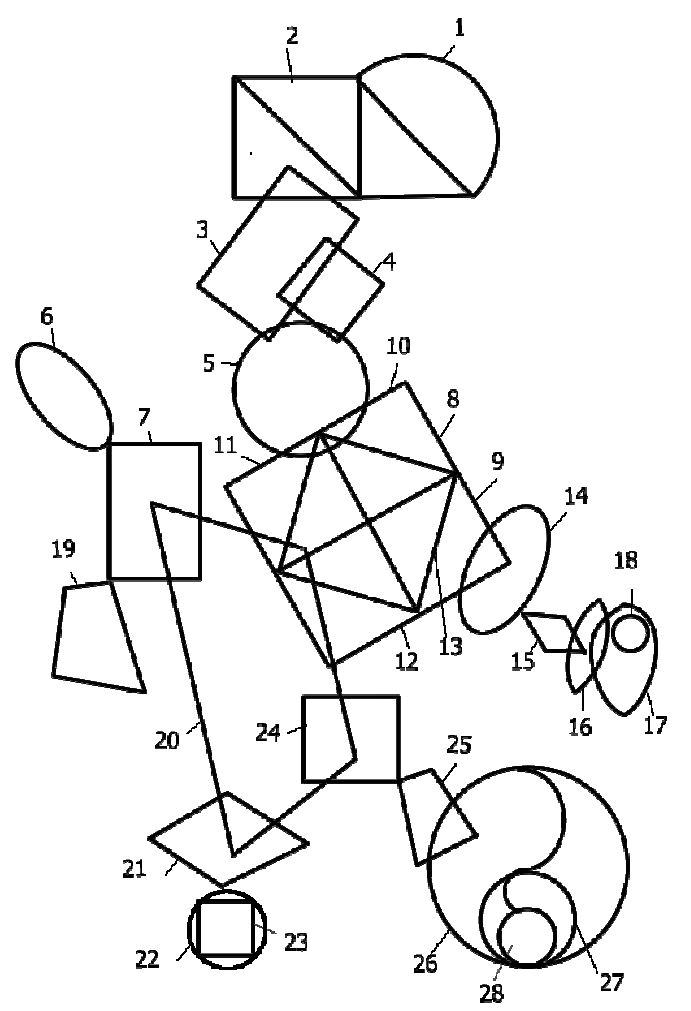

Figure 7. Student marks circles.

Similarly, during the third and final phase of the study, after the teaching intervention, the same test (FCPST) was given to all students in both the experimental and control groups as a post-test at the beginning of March 2012 to measure their improvement on circles and triangles separately.

\subsection{Research Design}

The present study was a quasi-experimental design with one experimental and one control groups. Eight first grade classes from Athens and two from Rethymno participated in this study. From the eight classes located in Athens, we randomly assigned four classes to the control group and the remaining four classes were assigned to the experimental group. We then randomly assigned one of the two classes from Rethymno to the control group and the other class to the experimental group. Therefore, five classes were in the control group $(n=121)$ and the remaining five classes were in the experimental group $(n=113)$.

\section{RESULTS}

A set of analyses was conducted to determine the effects of the mathematics intervention on first grade students' geometry knowledge for circles and triangles. The pre-test and post-test were taken by 234 students. Analysis of the data was carried out 
using the SPSS (ver. 19) statistical analysis computer program. The independent variables were the group (experimental group and control group) and the shape (circles, triangles, rectangles or squares). The dependent variable was the students' FCPST posttest score.

\subsection{Comparing the difficulty of understanding among shapes}

The first analysis was a paired t-test among the students' FCPST pre-test scores of circles, triangles, rectangles and squares. This was done in order to examine whether the concept of triangles is more difficult to understand than the other shapes. Also it was examined whether the concept of circles are more easy to understand than the other shapes. Moreover, the difficulty of squares is higher than circles and lower than rectangles. There were significant differences in the students' FCPST pre-test scores among circles $(M=.951, S D=.035)$ and triangles $(M=.837, S D=$ $.057), t(233)=29.033, p<.001$, rectangles $(M=.859, S D=.100)$, $t(233)=15.067, p<.001$, and squares $(M=.897, S D=.080)$, $t(233)=11.021, p<.001$. Also, there were significant differences in the students' FCPST pre-test scores among triangles $(M=.837$, $S D=.057)$ and rectangles $(M=.859, S D=.100), t(233)=-3.431$, $p<.001$, and squares $(M=.897, S D=.080), t(233)=-11.653$, $p<.001$. Moreover, there was a significant difference in the students' FCPST pre-test scores among rectangles $(M=.859, S D=$ $.100)$ and squares $(M=.897, S D=.080), t(233)=-6.452, p<.001$. The descriptive statistics for students' scores for circles and triangles are presented in Table 1.

Table 1. Descriptive statistics for students' FCPST pre-test scores

\begin{tabular}{|c|c|c|c|c|}
\hline & Circles & Triangles & $\begin{array}{l}\text { Recta } \\
\text { ngles }\end{array}$ & Squares \\
\hline & $\mathrm{M}, \mathrm{SD}$ & M, SD & M, SD & M, SD \\
\hline $\begin{array}{l}\text { Control and } \\
\text { Experimental }\end{array}$ & $\begin{array}{l}.951, \\
.035\end{array}$ & $.837, .057$ & $\begin{array}{l}.859 \\
.100\end{array}$ & $\begin{array}{l}.897 \\
.080\end{array}$ \\
\hline
\end{tabular}

\subsection{Evaluate the effectiveness of FCPSM for circles}

Before conducting the analysis of ANCOVA on the students' FCPST post-test scores for circles to evaluate the effectiveness of the intervention, checks were performed to confirm that there were no violations of the assumptions of homogeneity of variances and homogeneity of regression slopes [43]. The result of Levene's test when pre-test for circles was included in the model as a covariate was not significant, indicating that the group variances were equal, $F(1,232)=.342, p=.559$; hence the assumption of homogeneity of variance was not been violated.

Table 2. Comparison of student scores for circles in post-test: ANCOVA analysis

\begin{tabular}{|c|c|l|c|c|c|c|}
\hline Sources & $\begin{array}{c}\text { Type III } \\
\text { Sum of } \\
\text { Squares }\end{array}$ & df & $\begin{array}{c}\text { Mean } \\
\text { Squar } \\
\text { es }\end{array}$ & F & Sig. & $\eta^{2}$ \\
\hline Pre-test & .069 & 1 & .069 & 102.0 & .000 & .306 \\
\hline Group & .030 & 1 & .030 & 44.38 & .000 & .161 \\
\hline Error & .156 & 231 & .001 & & & \\
\hline
\end{tabular}

After adjusting for FCPST scores for circles in the pre-test (covariate), the following results were obtained from the analysis of covariance (ANCOVA). A statistically significant main effect was found for type of intervention on the FCPST post-test scores for circles, $F(1,231)=44.384, p<.001, \eta^{2}=.161$ (Table 2); thus the experimental group performed significantly higher in the FCPST post-test for circles than the control group.

\subsection{Evaluate the effectiveness of FCPSM for triangles}

Then, the analysis of ANCOVA on the students' FCPST post-test scores for triangles was performed to evaluate the effectiveness of the intervention. The result of Levene's test when pre-test for triangles was included in the model as a covariate was not significant, indicating that the group variances were equal, $F(1$, $232)=2.743, p=.099$; hence the assumption of homogeneity of variance was not been violated.

After adjusting for FCPST scores for triangles in the pre-test (covariate), the following results were obtained from the analysis of covariance (ANCOVA). A statistically significant main effect was found for type of intervention on the FCPST post-test scores for triangles, $\mathrm{F}(1,231)=66.558, \mathrm{p}<.001, \eta^{2}=.224$ (Table 3$)$; thus the experimental group performed significantly higher in the FCPST post-test for triangles than the control group.

Table 3. Comparison of student scores for triangles in posttest: ANCOVA analysis

\begin{tabular}{|c|c|l|l|l|l|l|}
\hline Sources & $\begin{array}{c}\text { Type III } \\
\text { Sum of } \\
\text { Squares }\end{array}$ & df & $\begin{array}{c}\text { Mean } \\
\text { Squar } \\
\text { es }\end{array}$ & F & Sig. & $\eta^{2}$ \\
\hline Pre-test & .106 & 1 & .106 & 30.05 & .000 & .115 \\
\hline Group & .234 & 1 & .234 & 66.55 & .000 & .224 \\
\hline Error & .812 & 231 & .004 & & & \\
\hline
\end{tabular}

\subsection{Evaluate the effectiveness of FCPSM for rectangles}

Then, the analysis of ANCOVA on the students' FCPST post-test scores for rectangles was performed to evaluate the effectiveness of the intervention.

After adjusting for FCPST scores for rectangles in the pre-test (covariate), the following results were obtained from the analysis of covariance (ANCOVA). A statistically significant main effect was found for type of intervention on the FCPST post-test scores for rectangles, $F(1,231)=58.108, \mathrm{p}<.001, \eta^{2}=.201$ (Table 4); thus the experimental group performed significantly higher in the FCPST post-test for rectangles than the control group.

Table 4. Comparison of student scores for rectangles in posttest: ANCOVA analysis

\begin{tabular}{|c|l|l|l|l|l|l|}
\hline Sources & $\begin{array}{l}\text { Type III } \\
\text { Sum of } \\
\text { Squares }\end{array}$ & df & $\begin{array}{c}\text { Mean } \\
\text { Squar } \\
\text { es }\end{array}$ & F & Sig. & $\eta^{2}$ \\
\hline Pre-test & 1.869 & 1 & 1.869 & 565.1 & .000 & .710 \\
\hline Group & .192 & 1 & .192 & 58.10 & .000 & .201 \\
\hline Error & .764 & 231 & .003 & & & \\
\hline
\end{tabular}




\subsection{Evaluate the effectiveness of FCPSM for squares}

Then, the analysis of ANCOVA on the students' FCPST post-test scores for squares was performed to evaluate the effectiveness of the intervention. The result of Levene's test when pre-test for squares was included in the model as a covariate was not significant, indicating that the group variances were equal, $\mathrm{F}(1,232)=.044, \mathrm{p}=.834$; hence the assumption of homogeneity of variance was not been violated.

After adjusting for FCPST scores for squares in the pre-test (covariate), the following results were obtained from the analysis of covariance (ANCOVA). A statistically significant main effect was found for type of intervention on the FCPST post-test scores for squares, $\mathrm{F}(1,231)=3.367, \mathrm{p}<.001, \eta 2=.068$ (Table 3 ); thus the experimental group performed significantly higher in the FCPST post-test for squares than the control group.

Table 5. Comparison of student scores for squares in post-test: ANCOVA analysis

\begin{tabular}{|c|l|l|l|l|l|l|}
\hline Sources & $\begin{array}{l}\text { Type III } \\
\text { Sum of } \\
\text { Squares }\end{array}$ & df & $\begin{array}{c}\text { Mean } \\
\text { Squar } \\
\text { es }\end{array}$ & F & Sig. & $\eta^{2}$ \\
\hline Pre-test & .252 & 1 & .252 & 115.6 & .000 & .334 \\
\hline Group & .120 & 1 & .120 & 55.26 & .000 & .193 \\
\hline Error & .503 & 231 & .002 & & & \\
\hline
\end{tabular}

Results of this study expand the research on the effects of appropriate software embedded in a computerized environment as a tool for visualization and mathematical reasoning used alongside with specially designed activities [26], [23], [32], [27], [28], [44], [29], [37], [39], [42]. Also, the outcomes of the present study create a new teaching model with computer and noncomputer activities based on the theoretical framework that blends together Realistic Mathematics Education of geometric thinking in primary school.

\section{DISCUSSION}

The general purpose of the study was to investigate the impact of instructional intervention using the First Class Primary Shape Model (specially designed mathematics activities and software based on Realistic Mathematics Education) for the purpose of teaching the basic geometrical concepts of circles, triangles, rectangles and squares in regards to the geometry competence of the first grade students of primary school. In this research, we found that it is more difficult for first grade students to understand the concept of triangles than the other shapes. These students carried a relatively great amount of geometric knowledge from kindergarten and as a result, it is possible that the students understand circles and their properties better than triangles, rectangles and squares because triangles are more complex shapes than the other shapes [26], [31]. Similar behavior we have with rectangles, which are more complex than squares and circles. Finally, squares are more complex than circles. Our findings agree with similar researches [38], [16], [37], [39] which implied that circles are simpler and triangles are most complex.

Moreover, we found that the students that were taught circles with educational intervention based on FCPSM had a significant improvement compared to those taught using the traditional teaching method according to the first grade curriculum (hypothesis 1). Therefore, the first hypothesis was confirmed.

Also, our findings suggest that the students were taught triangles with educational intervention based on FCPSM had a significant improvement compared to those taught using the traditional teaching method (hypothesis 2). As a result, the second research question answered positively.

Moreover, we found that the students that were taught rerctangles with educational intervention based on FCPSM had a significant improvement compared to those taught using the traditional teaching method according to the first grade curriculum (hypothesis 3). Therefore, the third hypothesis was confirmed.

In addition, we found that the students that were taught squares with educational intervention based on FCPSM had a significant improvement compared to those taught using the traditional teaching method according to the first grade curriculum (hypothesis 4). Therefore, the fourth hypothesis was confirmed.

Our results overlap with the results of other analogous studies which indicate the positive effects of a computer based-model of teaching geometry [26], [32], [37], [42]. Also, our results tend to confirm that other similar studies which indicate the positive effects of a computer based teaching model for geometric shapes [23], [28], [44], [29], [39], [45].

Moreover, an important statistical outcome of the present study was that the partial eta squared for triangles $(\eta 2=.224$ - Table 3$)$ is higher than it was for rectangles $(\eta 2=.201-$ Table 4$)$. Also, the partial eta squared for rectangles $(\eta 2=.201-$ Table 4$)$ is higher than it was for squares $(\eta 2=.193-$ Table 5). Finally, the partial eta squared for squares $(\eta 2=.193$ - Table 5) is higher than it was for circles $(\eta 2=.161-$ Table 2$)$.

This outcomes supports that, our teaching intervention had a somewhat greater impact in learning triangles than of learning circles for first grade students. Also, the present study demonstrates that our first grade teaching process, the noncomputer based mathematics activities and the computer based mathematics activities, may support the learning of both difficult and simple mathematics in the primary school level. Our findings agree with other similar researches supporting the effective role of ICT in education and more specifically in mathematical reasoning [31], [23], [45], [24], [28], [25], [30], [46].

The above discussion should be referenced in light of some of the limitations of this study. The first limitation of the study is that the data collected was from the participants residing the cities of Athens and Rethymno. The second limitation was the generalizability of this study which was limited to participants attending public schools. Therefore, the results from this research can be generalized only to similar groups of students. The results may not adequately describe students from other regions of Greece. However, as the study was of small scale and context specific, any application of the findings should be done with caution.

Furthermore, the undertaken computer assisted educational procedure revealed an extended interest for the tasks involved from the part of the students. It is an ongoing challenge for the reflective teacher to decide how this technology can be best utilized in education; especially in light of the current researches on the effects of such an implementation. This study is simply one 
small piece in the puzzle of geometry education in primary schools.

\section{REFERENCES}

[1] Druin, A., \& Fast, K. 2002. The Child as Learner, Critic, Inventor, and Technology Design Partner: An Analysis of Three Years of Swedish Student Journals. The International Journal for Technology and Design Education, 12(3), 189213.

[2] Passey, D. 2006. Technology enhancing learning: analysing uses of information and communication technologies by primary and secondary school pupils with learning frameworks. Curriculum Journal, 17(2), 139-166. DOI= 10.1080/09585170600792761.

[3] Zaranis, N. 2011. The influence of ICT on the numeracy achievement of Greek kindergarten children, In A. Moreira, M.J. Loureiro, A. Balula, F. Nogueira, L. Pombo, L. Pedro, P. Almeida, (Eds.) Proceedings of the 61st International Council for Educational Media and the XIII International Symposium on Computers in Education (ICEM\&SIIE'2011) Joint Conference, 390-399, University of Aveiro, Portugal, 28-30 September 2011.

[4] Plowman, L., \& Stephen, C. 2003. A 'benign addition'? Research on ICT and pre-school children. Journal of Computer Assisted Learning, 19(2) 149-164.

[5] Chen, J. \& Chang, C. 2006. Using computers in early childhood classrooms: Teachers' attitudes, skills and practices. Journal of Early Childhood Research, 4(2), 169188.

[6] Zaranis, N., \& Oikonomidis, V. (2009) ICT in Preschool Education. Athens: Grigoris Publications [Text in Greek].

[7] Bayraktar, S. 2002. A meta-analysis of the effectiveness of computer-assisted instruction in science education. Journal of Research on Technology in Education, 34(2), 173-188.

[8] Clements, D. H. 2002. Computers in Early Childhood Mathematics. Contemporary Issues in Early Childhood, 3(2), 160-181.

[9] McKenney, S., \& Voogt, J. 2009. Designing technology for emergent literacy: the pictopal initiative. Computers and Education, 52, 719-729.

[10] Trundle, K. C., \& Bell, R. L. 2010. The use of a computer simulation to promote conceptual change: A quasiexperimental study. Computers and Education, 54(4), 10781088.

[11] Dodge, D., Colker, L., \& Heroman, C. 2003. The creative curriculum for early childhood. Washington, DC: Teaching Strategies.

[12] Morrow, L., Gambrell, L., \& Pressley, M. 2003. Best practices in literacy education. New York: Guilford.

[13] Ihmedieh, F. 2010. The role of computer technology in teaching reading and writing: Early childhood teachers' beliefs and practices. Journal of Research in Childhood Education, 24(1). 60-79.

[14] Judge, S. 2005. The impact of computer technology on academic achievement of young African American children. Journal of Research in Childhood Education, 20(2). 91-101.
[15] Clements, D. H. \& Sarama, J. 2003. Strip mining for gold: Research and policy in educational technology-a response to "Fool's Gold". Association for the Advancement of Computing in Education (AACE) Journal, 11(1), 7-69.

[16] Walcott , C., et al. 2009. Making sense of shape: An analysis of children's written responses, Journal of Mathematical Behavior, 28, 30-40.

[17] Dwyer, J. 2007. Computer-based Learning in a primary school: Differences between the early and later years of primary schooling. Asia-Pacific Journal of Teacher Education, 35(1), 89-103. DOI= 10.1080/13598660601111307.

[18] Lee, Y. 2009. Pre-K Children's Interaction with Educational Software Programs: An Observation of Capabilities and Levels of Engagement. Journal of Educational Multimedia and Hypermedia, 18(3), 289-309.

[19] Fisher, T., Denning, T., Higgins, C., \& Loveless, A. 2012. Teachers' knowing how to use technology: exploring a conceptual framework for purposeful learning activity. Curriculum Journal, 23(3), 307-325. DOI= 10.1080/09585176.2012.703492.

[20] Burnett, C. 2009. Research into literacy and technology in primary classrooms: an exploration of understandings generated by recent studies. Journal of Research in Reading, 32(1), 22-37. DOI= 10.1111/j.1467-9817.2008.01379.x.

[21] Sutherland, R. et al., 2004. Transforming teaching and learning: embedding ICT into everyday classroom practices. Journal of Computer Assisted Learning, 20(6), 413-425. doi: 10.1111/j.1365-2729.2004.00104.x.

[22] Sife, A. S., Lwoga, E.T., \& Sanga, C. 2007. New technologies for teaching and learning: Challenges for higher learning institutions in developing countries. International Journal of Education and Development using Information and Communication Technology (IJEDICT), 3(2), 57-67.

[23] Dimakos, G., \& Zaranis, N. 2010. The influence of the Geometer's Sketchpad on the Geometry Achievement of Greek School Students. The Teaching of Mathematics, 13(2), 113-124. (retrieved 29/3/2011, http://elib.mi.sanu.ac.rs/files/journals/tm/25/tm1324.pdf).

[24] Hardman, J. 2005. An exploratory case study of computer use in a primary school mathematics classroom: New technology, new pedagogy? Perspectives in Education, 23(4), 99-111.

[25] Keong, C. C., Horani, S., \& Daniel J., 2005. A Study on the Use of ICT in Mathematics Teaching. Malaysian Online Journal of Instructional Technology (MOJIT), 2(3), 43-51.

[26] Bobis, J., et al., 2005. Supporting Teachers in the Development of Young Children's Mathematical Thinking: Three Large Scale Cases. Mathematics Education Research Journal, 16(3), 27-57.

[27] Gersten, R., Jordan, N., \& Flojo, J. 2005. Early Identification and Interventions for Students with Mathematics Difficulties. Journal of Learning Disabilities, 38(4), 293-304.

[28] Howie, S., \& Blignaut, A.S. 2009. South Africa's readiness to integrate ICT into mathematics and science pedagogy in secondary schools. Educ Inf Technol, 14:345-363. DOI= 10.1007/s10639-009-9105-0. 
[29] Trouche, L., \& Drijvers, P. 2010. Handheld technology for mathematics education: flashback into the future. ZDM: The International Journal on Mathematics Education, 42(7), 667681. doi: 10.1007/s11858-010-0269-2.

[30] Vale, C., \& Leder, G. 2004. Student views of computerbased mathematics in the middle years: does gender make a diference? Educational Studies in Mathematics, 56, 287-312.

[31] Clements, D. H., \& Sarama, J. 2004. Building Blocks for early childhood mathematics. Early Childhood Research Quarterly, 19, 181-189.

[32] Dissanayake, S.N., Karunananda, A.S., \& Lekamge, G.D., 2007. Use of Computer Technology for the teaching of primary school mathematics. OUSL Journal, 4, 33-52.

[33] Freudenthal, H. 1968. Why to Teach Mathematics so as to Be Useful? Educational Studies in Mathematics, 1, 3-8.

[34] Van den Heuvel-Panhuizen M., \& Wijers, M. 2005. Mathematics standards and curricula in the Netherlands. Zentralblatt für Didaktik der Mathematik (ZDM), 37 (4), 287-307.

[35] Van den Heuvel-Panhuizen, M. 2001. Realistic Mathematics Education as Work in Progress. In F. L. Lin (Ed.) Common Sense in Mathematics Education, Proceedings of 2001, the Netherlands and Taiwan Conference on Mathematics Education, Taipei, Taiwan, 19 - 23 November 2001, 1-40.

[36] Van den Heuvel-Panhuizen, M. \& Buys, K. (Eds.) 2008. Young children learn measurement and geometry. A learning-teaching trajectory with intermediate attainment targets for the lower grades in primary school. Rotterdam /Tapei: Sense Publishers.

[37] Wong, W. K., et al., 2007. LIM-G: Learner-initiating instruction model based on cognitive knowledge for geometry word problem comprehension. Computers and Education Journal, 48(4), 582-601.

[38] Satlow, E. \& Newcombe, N., 1998. When is a triangle not a Triangle? Young children's developing concepts of geometry shape. Cognitive Development, Ablex Publishing,13, 547559.

[39] Wong, W.-K., et al., 2011. Using Computer-Assisted Multiple Representations in Learning Geometry Proofs. Educational Technology \& Society, 14 (3), 43-54.

[40] Clements, D. H., Swaminathan, S., Zeitler-Hannibal, M., \& Sarama, J. 1999. Reviewed work(s): Source: Journal for Research in Mathematics Education, 30(2), 192-212

[41] Clements, D. H., \& Battista, M. T. 1992. Geometry and spatial reasoning, In D. A. Grouws (Ed.), Handbook of research on mathematics teaching and learning, 420-464, New York: Macmillan.

[42] Zaranis, N. 2012. The use of ICT in Preschool Education for geometry teaching. In R. Pintó, V. López, \& C. Simarro (Eds.) Proceedings of the 10th International Conference on Computer Based Learning in Science, Learning Science in the Society of Computers, 256-262, Centre for Research in Science and Mathematics Education (CRECIM), Barcelona, Spain, 26-29 June 2012.

[43] Pallant, J. 2001. SPSS survival manual. Buckingham, UK: Open University Press.

[44] Starkey, P., Klein, A., \& Wakeley, A. 2004. Enhancing young children's mathematical knowledge through a prekindergarten mathematics intervention. Early Childhood Research Quarterly, Elsevier, 19, 99-120.

[45] Zaranis, N., \& Oikonomidis, V. 2009. ICT in Preschool Education. Athens: Grigoris Publications [Text in Greek].

[46] Furner, J.M., \& Marinas, C.A., 2007. Geometry Sketching Software for Elementary Children: Easy as 1, 2, 3. Eurasia Journal of Mathematics, Science \& Technology Education, 3(1), 83-91.

\section{Columns on Last Page Should Be Made As Close As Possible to Equal Length}

